\title{
MuSAE: A European Project for the Diffusion of Energy and Environmental Planning in Small-Medium Sized Municipalities
}

\author{
Giorgio Baldinelli ${ }^{1, *}$, Francesco Bianchi ${ }^{1}$, Matteo Cornicchia ${ }^{1}$, Francesco D'Alessandro ${ }^{1}$, \\ Gabriele De Micheli ${ }^{2}$, Gaia Gifuni ${ }^{2}$, Andrea Monsignori ${ }^{3}$, Maria Ruggiero ${ }^{3}$, Michele Cenci ${ }^{3}$, \\ Fabrizio Bonucci ${ }^{4}$, Francesco Zepparelli ${ }^{5}$ and Claudio Mariotti ${ }^{6}$
}

Received: 27 October 2015; Accepted: 3 December 2015; Published: 11 December 2015

Academic Editor: Marc A. Rosen

1 CIRIAF-University of Perugia, Via G. Duranti 67, 06125 Perugia, Italy; bianchi.unipg@ciriaf.it (F.B.); cornicchia.unipg@ciriaf.it (M.C.); francesco.dalessandro@unipg.it (F.D.)

2 Energy Office, Open Data, Technological System, Municipality of Perugia, Piazza Morlacchi 23, 06123 Perugia, Italy; g.demicheli@comune.perugia.it (G.D.M.); g.gifuni@comune.perugia.it (G.G.)

3 Energy, Environmental Quality, Waste and Mining Department, Umbria Region, Piazza Partigiani 1, 06121 Perugia, Italy; amonsignori@regione.umbria.it (A.M.); mruggiero@regione.umbria.it (M.R.); mcenci@regione.umbria.it (M.C.)

4 Public Works Office, Municipality of Umbertide, Piazza Matteotti 1, 06019 Umbertide (PG), Italy; f.bonucci@comune.umbertide.pg.it

5 Environment Office, Municipality of Marsciano, Largo Giuseppe Garibaldi 1, 06055 Marsciano (PG), Italy; f.zepparelli@comune.marsciano.pg.it

6 Municipality of Lisciano Niccone, Piazza della Repubblica 3, 06060 Lisciano Niccone (PG), Italy; uff.tec1@montone.org

* Correspondence: giorgio.baldinelli@unipg.it; Tel.: +39-075-585-3868; Fax: +39-075-585-3697

\begin{abstract}
The basic idea of the EU LIFE+ 2011 project MuSAE ("Municipalities Subsidiarity for Actions on Energy", code LIFE11 ENV/IT/000016) consists of transferring the skills and experience related to energy planning, acquired by the leading beneficiary, the Municipality of Perugia, to three small- or medium-sized Umbrian Municipalities (Marsciano, Umbertide and Lisciano Niccone). This transfer is aimed, among other objectives, at the drafting of the Municipal Energy and Environmental Plan (MEEP) and the opening of an energy information office in each partner Municipality, in cooperation with CIRIAF and Umbria Region. The present paper provides a summary of MuSAE activities, analyzing the procedures and modalities of implementation of the various phases of the MEEPs, on the basis of the experience gained over the years through the collaboration with the Municipality of Perugia and adapted to smaller territories such as those represented by the other partner Municipalities. A summary of the dissemination activities and pilot projects is also presented, testifying the first concrete results of the planning activity developed by each administration within the project.
\end{abstract}

Keywords: energy planning; environmental planning; energy saving; renewable energy; environmental impact; sustainability

\section{Introduction}

Mass media, institutional conventions, and green economy companies debate about environmental problems and use of renewable energy sources. On the other side, citizens and companies do not find practice solutions applicable to their problems or do not know the correct way to reduce their carbon footprint and to improve their position in different sectors, like mobility, heating and cooling 
energy saving. People could not be aware of the opportunities, the economic advantages, and the authorization issues, to convince them to spend money or change behaviors for improving their comfort, quality of life and give a good contribution to the environment. Sometimes, the inadequate knowledge of environmental topics causes concerns and diffidence towards innovative solutions.

Starting from the oil crisis of the 1970s, the International Energy Agency has begun to give importance to integrated energy planning (IEP), which was mainly managed at the national level through a centralized approach [1]. Municipalities and local authorities started to gain a central role in the definition of energy and sustainability policies from the 1990s [2-4], when it began clear that local authorities were key actors in climate change policies and that local initiatives should be fundamental parts of national climate programs [5]. A number of networks have been created worldwide to link Municipalities and public authorities in order to share strategies and to find solutions to common problems, such as Energy Cities [6], Climate Alliance [7], Local Governments for Sustainability [8] and the European Covenant of Mayors [9]. However, the difference between the peculiar conditions of each territory, including different size and population, can make difficult to transfer the experience and the best practices from one local authority to another [1].

The importance of the coordination of energy planning at national and local level has been analyzed in several research studies [2,10-12]. The central government is responsible for long-term strategies and for the definition of incentive schemes, and this is crucial for local actions to be successful. On the contrary, it happens that the national government is considered an obstacle for local authorities to define their strategies. For instance, the Danish Government is worried by the increasing number of municipalities that are developing their own energy plans that are too different among them. In this way, a national goal could not be easily achieved [2].

Municipalities can play several roles in energy and environmental planning. They own public properties, such as buildings and vehicle fleets, and are shareholders in local energy utilities [13]. A study estimated that UK local authorities could save 5.5 million tonnes of $\mathrm{CO}_{2}$ a year if all the owned buildings and vehicle fleets were carbon neutral [14]. Other studies proved that the improvement of the energy efficiency of public buildings, by means of increased thermal insulation of the envelope, high-efficiency lighting and appliances, and a more conscious behavior of the users, can lead to fast and impacting results in terms of economic and energy savings $[15,16]$. The implementation of street lighting measures, such as the substitution of traditional lamps with high-efficiency LEDs, can also lead to important reductions in the energy consumption of the Municipality. Other main roles of the municipalities and other local authorities can be identified in providing information and advice on energy-related topics. In particular, Municipalities can be considered as fundamental actors in fostering the use of renewable energy sources (RES), by means of focused communication strategies, aimed at highlighting the advantages and easing the administrative procedures, and implementation of pilot projects. The latter aspect can also represent an instrument to contrast the public opposition that sometimes can be addressed to the installation of some RES facilities [17,18].

Therefore, while examples and studies about the transfer of best practices between Municipalities exist, and the importance of urban energy planning has been sufficiently discussed, few examples reporting the influence of energy and environmental planning of small and medium sized Municipalities can be found in the literature. The latter, together with the knowledge transfer in sustainable energy development between a mentor Municipality and small mentee Municipalities, constitute the central issues of the MuSAE project, which will be deeply discussed in the paper.

\section{The Project MuSAE}

The project MuSAE ("Municipalities Subsidiarity for Actions on Energy") (code LIFE11 ENV/IT/000016), funded under the LIFE+ Program in 2011, is based on the assumption that shared strategies concerning energy savings and renewable energy sources result critical for the achievement of the objectives set by the strategy “Europe 20/20/20". Besides, it arises from the awareness that local 
authorities are required to play a decisive role in achieving the commitments made by EU in order to promote a new model of sustainable development. The project involves six partners of central Italy: the Municipality of Perugia, the leading beneficiary, the Municipalities of Marsciano, Umbertide, and Lisciano Niccone, as targets of the skills transfer from the leading beneficiary (Figure 1 and Table 1), the Umbria Region, in charge of the coordination with regional policies and of the dissemination activities, and the Inter-university Research Center on Pollution and Environment (CIRIAF), an inter-university research center with the role of scientific and technical partner. The project started in September 2012 and ended in June 2015, for a total duration of 34 months [19].

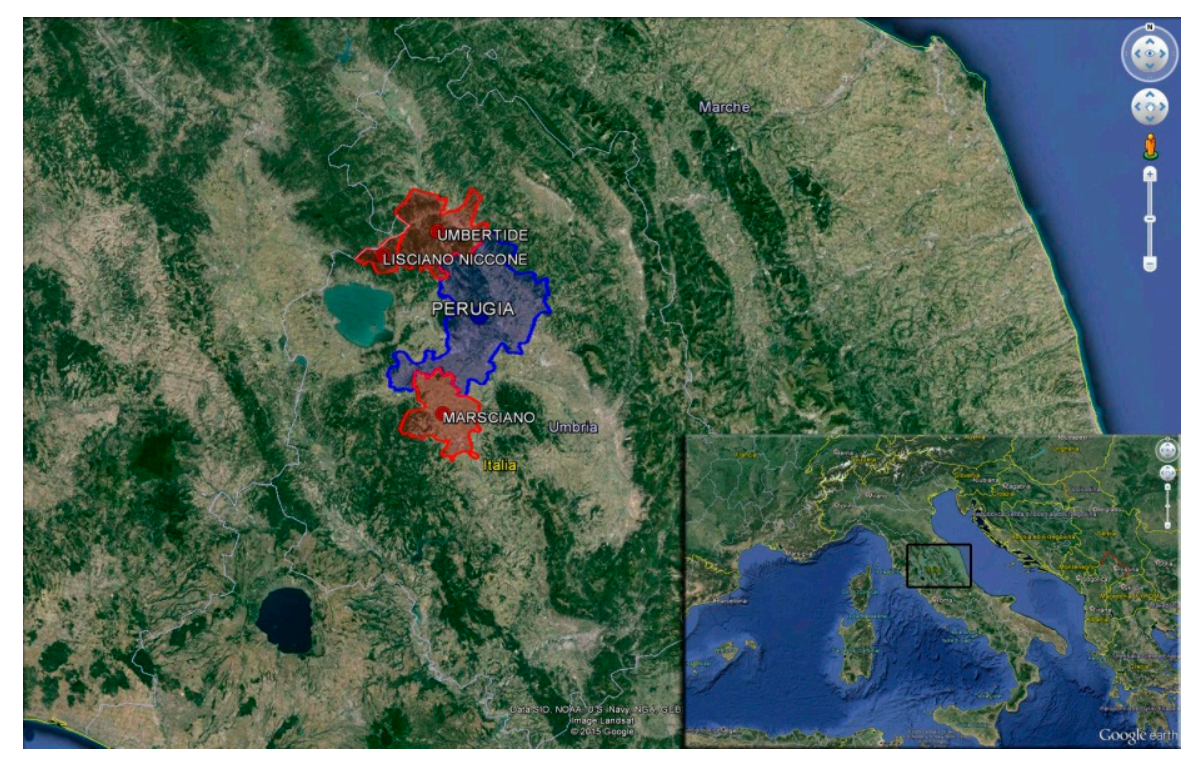

Figure 1. Aerial view of the Municipalities involved in the project (Source: Google Earth).

Table 1. Area and population of the four partner municipalities.

\begin{tabular}{ccc}
\hline Municipality & Area $\left[\mathbf{k m}^{2}\right]$ & Population \\
\hline Perugia & 449.51 & 168,169 \\
Umbertide & 200.83 & 16,890 \\
Marsciano & 161.49 & 18,770 \\
Lisciano Niccone & 35.18 & 627 \\
\hline
\end{tabular}

The acronym MuSAE contains the following topics, which represent the pillars of the project:

- Municipality: The Umbrian territorial texture consists mainly of small towns playing a crucial role in spreading the culture of energy, environment and sustainability

- Subsidiarity: The public bodies, partners of the project, work synergistically to achieve shared goals, providing their experience and skills and giving support each other in the joint definition of the Municipal Energy and Environmental Plan (named MEEP in the following) and in the preparation of the pilot projects for energy efficiency and renewable sources. In particular, the Municipality of Perugia, the Umbria Region capital and project leader, has gained a long-standing experience in energy planning and it is asked to transfer its knowledge to the other partners

- Actions: the main project actions are listed below:

- Realization of the Environmental Municipal Energy Plans (MEEP) of the three small Municipalities 
- Definition of Guidelines and pilot schemes, aimed (i) at providing a complete picture of the regional, national and European energy and environmental legislation; (ii) at defining the procedures for the transfer of the planning experiences and skills from the leading Municipality to the others; and (iii) at identifying the professional skills necessary for a fruitful application of the MEEPs

- Realization of a pilot project in each partner Municipality, related to energy saving, use of renewable energy sources or sustainable mobility, in order to share best practices with citizens and other stakeholders and increase their awareness

- Opening of an Energy Info-Desk in each Municipality; it is a qualified service dedicated to businesses, professionals, citizens and all local stakeholders, to facilitate investments, to provide information on the Municipal Energy and Environmental Plan, and to illustrate incentives available and authorization procedures necessary for renewable energy plants construction or interventions for energy efficiency enhancement

- Communication activities: Forums, seminars and conferences at municipal, regional, national and European level were organized to inform and make aware citizens and stakeholders of energy and environmental issues

- Network activities at national and European level by interacting with other projects, mainly funded under the LIFE+ program

- Energy: clean and smart energy in the territories of the project: The goals of MuSAE are consistent with the "20-20-20" EU strategy that aims to achieve by 2020:

- reduction of greenhouse gas emissions by $20 \%$ compared to 1990 levels

- increase of energy efficiency by $20 \%$

- increase of renewable energy by $20 \%$

\section{Objectives of the Project}

The energy sector is responsible for a substantial portion of the negative effects of the human footprint on the environment [20,21]. The European Directive 2009/28/EC [22], usually known as "20-20-20", requires each member state to cover by 2020 a share of its gross final energy consumption with renewable sources. As a consequence, there has been a breakdown of the various Member States (Italy's share is equal to $17.0 \%$ ), which in turn sees a division among the single Regions (Umbria's share: $13.7 \%$ ) [23], and then also to the municipalities, in order to empower local authorities through incentives and sanctions, taking into account the peculiarities of each territory.

Article 5 of the Italian Law 10/91 [24] obliges the Municipalities with more than 50,000 citizens to adopt a specific tool for environmental and energy planning of its territory: the Municipal Energy and Environmental Plan (MEEP) allows the administrators to prepare the balance sheet of the demand (consumption) and supply (production) of energy in their territories, and consequently to define aware and coherent strategies.

The MEEP is slightly different from the Sustainable Energy Action Plan (SEAP), required when signing the Covenant of Mayors; differences are highlighted in Section 4.

Italy, as well as many other European countries, has experienced a historically urban development characterized primarily by small towns and villages: the latest ISTAT (Italian Institute of Statistics) report confirms this finding, indicating that $66 \%$ of the Italian population lives in medium and small towns, with less than 50,000 inhabitants (Figure 2). In addition, the European strategy "20-20-20" sets targets for all Member States, without distinguishing the dimensions of the individual Municipalities. 


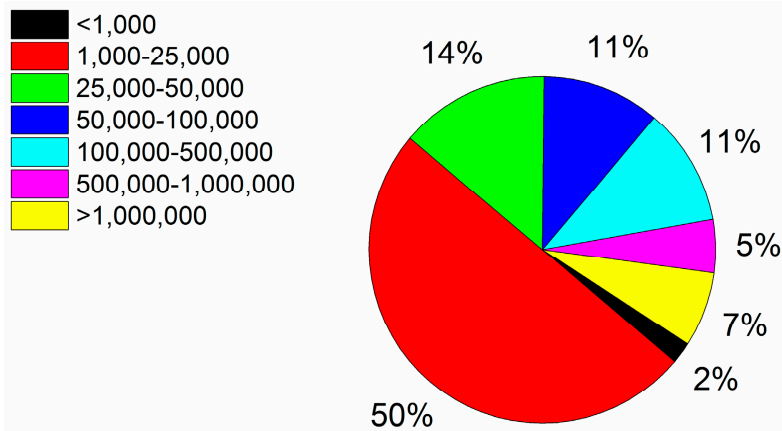

Figure 2. Distribution of inhabitants in Italian Municipalities divided by size (Source: Italian Institute of Statistics (ISTAT)).

Therefore, small size local communities could give a significant added value to the achievement of these objectives; however, in most cases, they are not provided by sufficient skills and resources to address this challenge and they are not obliged by law to adopt tools for energy-environmental planning.

Thus, one of the main objectives of the project MuSAE is the implementation of a tool to help small and medium-sized Municipalities in all aspects related to the energy and environmental planning, i.e.,:

- the building of an accounting system of energy and emissions

- the identification of the dynamics of future development, with forecasts for energy scenarios

- the proposal of interventions to achieve energy savings

- the promotion of a proper deployment of renewable and alternative energy sources

- the reduction of green-house gases emissions

- the constitution of a resilient territorial system, able to renew itself and to adapt to the climate change

These topics will be addressed later in this paper, along with some information on the pilot projects carried out by the project partners Municipalities.

\section{Comparison between the Municipal Energy and Environmental Plan (MEEP) and the Sustainable Energy Action Plan (SEAP)}

As already stated in previous sections, the MEEP is a compulsory plan that Italian Municipalities with more than 50,000 inhabitants are obliged to prepare, while the Sustainable Energy Action Plan (SEAP) is part of the commitments that a Municipality (or a group of them) undertake when voluntarily signing the Covenant of Mayors. The latter is a well-known initiative promoted by the European Commission to actively involve European cities in a strategy moving towards energy and environmental sustainability.

Table 2 summarizes a comparison of the fundamental aspects between the Covenant of Mayors with its SEAP, and the MEEP envisaged under the MuSAE project, analyzing the similarities and the main differences. This assessment has been made easier thanks to the fact that the Municipality of Umbertide was already a signatory of the Covenant of Mayors, therefore, its SEAP was available. It is clear how the adoption of a Municipal Energy and Environmental Plan actually opens up the path for adhesion to the Covenant of Mayors, if the municipal administration so wishes. The technical work required to develop a MEEP can be considered equivalent (and practically identical) to the effort necessary for the creation of a SEAP. 
Table 2. Comparison between the SEAP and the MEEP of the MuSAE project.

\begin{tabular}{|c|c|c|c|}
\hline & SEAP-Covenant of Mayors & MEEP-MuSAE Project & Comparison \\
\hline Objectives & $\begin{array}{l}\text { To make a concrete pledge in the fight } \\
\text { to reduce by over } 20 \% \text { greenhouse gas } \\
\text { emissions via local policies and } \\
\text { measures, which increase the use of } \\
\text { renewable energy sources, improve } \\
\text { energy efficiency and implement ad } \\
\text { hoc programs for energy saving and } \\
\text { the rational use of energy. }\end{array}$ & $\begin{array}{l}\text { To provide the administrations } \\
\text { of small- and medium-sized } \\
\text { Municipalities with tools and } \\
\text { methods to plan local, } \\
\text { short-term actions: the plans } \\
\text { guarantee immediate effects in } \\
\text { terms of the development of } \\
\text { renewable sources and of the } \\
\text { reduction of energy } \\
\text { consumption, with the relative } \\
\text { environmental benefits, } \\
\text { provided that administrations } \\
\text { commit themselves on doing so. }\end{array}$ & $\begin{array}{l}\text { The objective is common to both } \\
\text { projects: to move towards a } \\
\text { sustainable environment. To adhere } \\
\text { to the Covenant of Mayors, there } \\
\text { are minimum requirements to } \\
\text { comply with and objectives to } \\
\text { reach, whereas the MEEP } \\
\text { envisaged by the MuSAE project } \\
\text { provides only the local } \\
\text { administrations of a guideline on } \\
\text { how to achieve these objectives. } \\
\text { Both processes urge local } \\
\text { communities and all the } \\
\text { stakeholders to become actively } \\
\text { involved. In both cases, it results } \\
\text { extremely important to share the } \\
\text { experience and knowledge with } \\
\text { the other territorial groups and to } \\
\text { organize forums, seminars and } \\
\text { conferences, which enable the } \\
\text { citizens to come into direct contact } \\
\text { with the opportunities and } \\
\text { advantages offered. }\end{array}$ \\
\hline
\end{tabular}

ACTIVATION: identification of the

players and the responsibilities of each one.

- $\quad$ Political pledge and signing of the Covenant

- $\quad$ to adapt the town administrative structures with the aim of identifying a suitable organizational structure (managers, work groups, etc.)

- To identify and obtain the stakeholders' support
PREPARATORY ACTIONS: to execute and participate in the design and planning with the main stakeholders.
The preparation and the decision making contained in a SEAP require a higher commitment and involvement compared to what is required to draw up and approve a MEEP.
SEAP:

- evaluation of the current picture

- draft of the BEI (Baseline Emission Inventory)

- definition of the objectives, of the long-term vision and the evaluation of the action potential in terms of reduction in the final energy consumption of the various sectors, of the increase in the renewable energy local production sources or other sources with low environmental impact, and a reconstruction of the possible evolving scenarios for the local energy system

- $\quad$ assignment of levels of priority to the various actions to implement

- identification and analysis of the most suitable tools to implement the chosen actions (tools of motivation, management and verification, etc.) and quantification of the contribution that each action may provide to achieve the objectives

- approval and submission of the plan
MEEP:

- definition of the legislative framework and preliminary objectives of the planning

- analysis/specification of the territory (climate, demographic, economic data)

- configuration of the energy system: MEB (Municipal Energy Balance)

- estimate of emissions linked to energy consumption

- evaluation of the possible actions and usability of the renewable and assimilated resources

- reconstruction of the possible scenarios evolving in the local energy system, to identify the potential for the actions to be implemented (both from a demand and offer point of view)
Both documents are based on a study/specification of the territory and energy flows with the implementation of the BEI for the SEAP and the MEP for the MEEP and both evaluate possible future actions. The main difference lies in the planning of the actions. In the SEAP case, the actions are very specific and detailed both from the project design and from the economic point of view and they are, above all, binding. The MEEP actions are not given in detail. However, their efficacy is estimated so that the municipal administration may then act freely. Another difference consists on the use of emission factors: in the MEEP, the choice is quite free (in the case of the MuSAE project, the IPCC data were used), whereas in the case of the SEAP, it is necessary to use the emission factors given in the related guidelines which, in any case, are represented by the standard factors introduced by the IPCC or the LCA factors. 
Table 2. Cont.

\begin{tabular}{|c|c|c|c|}
\hline & SEAP-Covenant of Mayors & MEEP-MuSAE Project & Comparison \\
\hline Implementation & $\begin{array}{l}\text { Execution of the entire process thanks } \\
\text { to the implementation of the actions } \\
\text { envisaged by the SEAP. } \\
\text { - Feasibility plan and any loans } \\
\text { - identification of the tools for } \\
\text { implementation (organization, } \\
\text { public tenders, third party } \\
\text { loans, etc.) } \\
\text { implementation of the actions }\end{array}$ & $\begin{array}{l}\text { Description of the procedures to } \\
\text { put the Plan into action, the } \\
\text { tools to implement and manage } \\
\text { the planning: } \\
\text { - } \quad \text { identification of operative, } \\
\text { financial, legislative, } \\
\text { training and } \\
\text { information tools } \\
\text { planning of pilot actions } \\
\text { such as the energy } \\
\text { refurbishing of public } \\
\text { buildings, the } \\
\text { implementation of } \\
\text { innovative systems using } \\
\text { renewable sources, } \\
\text { incentives to use thermal } \\
\text { solar panels, etc. } \\
\text { opening of "one-stop } \\
\text { energy" desks and services } \\
\text { dedicated to all } \\
\text { individuals involved in the } \\
\text { planning activity (citizens, } \\
\text { enterprises), which } \\
\text { represent a meeting point } \\
\text { for the various institutions } \\
\text { involved in the energy and } \\
\text { the environment issues }\end{array}$ & $\begin{array}{l}\text { These stages result very similar and } \\
\text { could be easily integrated, in fact, it } \\
\text { is possible that a Municipality } \\
\text { decides to draw up a MEEP, } \\
\text { wishing to adhere to the Covenant } \\
\text { of Mayors at a later date. In this } \\
\text { case, all the work already carried } \\
\text { out to draw up a MEEP would } \\
\text { facilitate their adhesion to the } \\
\text { Covenant and achieve its } \\
\text { objectives. }\end{array}$ \\
\hline Monitoring & $\begin{array}{l}\text { Monitoring of the initiatives taken } \\
\text { over time and their efficacy in terms of } \\
\text { variation in emissions, which } \\
\text { inventory has to be updated, for the } \\
\text { purpose of verifying whether the } \\
\text { target is getting closer or further away } \\
\text { and, therefore, of putting in place any } \\
\text { necessary corrective actions: } \\
\text { - monitoring: regular update of } \\
\text { the MEI (Monitoring Emission } \\
\text { Inventories) and quantification } \\
\text { of the benefit obtained with } \\
\text { the actions } \\
\text { submission of the } \\
\text { implementation report of } \\
\text { the Plan } \\
\text { review: verification and } \\
\text { eventual re-planning }\end{array}$ & $\begin{array}{l}\text { To monitor and assess the } \\
\text { efficacy of the actions planned } \\
\text { and implemented after the } \\
\text { adoption of the MEEP, a } \\
\text { simplified easy-to-use method } \\
\text { was developed within the } \\
\text { MuSAE project. For each action } \\
\text { implemented, a normalized } \\
\text { saving effect is given in terms of } \\
\mathrm{CO}_{2 \mathrm{eq}} \text { (for example, kilograms } \\
\text { of } \mathrm{CO}_{2 \text { eq, }} \text { saved for each kWh of } \\
\text { energy produced by wind } \\
\text { farms); the total saving depends } \\
\text { on the potential of the each } \\
\text { particular action in the specific } \\
\text { territory. Thus, it is possible to } \\
\text { assess the effect that the action } \\
\text { might produce in the future, } \\
\text { and its actual effect once it is } \\
\text { implemented. The annual } \\
\text { monitoring of the MEB is in } \\
\text { itself a form of monitoring. }\end{array}$ & $\begin{array}{l}\text { The Covenant of Mayors envisages } \\
\text { the submission of the MEI every } \\
\text { two years: Any failure to achieve } \\
\text { the objectives to reduce emissions } \\
\text { as indicated in the Action Plan, due } \\
\text { to the failed and/or insufficient } \\
\text { implementation of the plan and/or } \\
\text { failure to submit the biennial report } \\
\text { for two consecutive periods, results } \\
\text { in exclusion from the Covenant. } \\
\text { The adoption of a MEEP is less } \\
\text { binding from the monitoring point } \\
\text { of view. However, it is opportune } \\
\text { to carry it out every year, even after } \\
\text { the adoption, in order to check the } \\
\text { progresses made. }\end{array}$ \\
\hline
\end{tabular}

\section{Guidelines for the Implementation of the Municipal Energy and Environmental Plan (MEEP)}

The basic idea of the MuSAE project consists of transferring the skills acquired by the Municipality of Perugia in the realization of its MEEP [25], developed with the technical and scientific support of CIRIAF, to the other Municipalities of the Umbria Region. Except for the larger ones, most of the medium and small size Municipalities in the Region has a small number of employees in their technical department, having to deal with a large number of tasks.

One of the main results of the knowledge transfer from Perugia to the other Municipalities consisted of the preparation of the Competences Catalogue. It started with the process of shared analysis on the professionals and the training requirements outlined by the new tools of environmental energy programming. The identification of the professionals character was defined in a first proposal, to be exploited for a screening of the knowledge, skills and competence required (ideal type), both specific and transversal. This catalogue was verified among the staff of public authorities involved, to highlight the spread of knowledge, skills and expertise possessed compared to those 
in the target. To deepen the training need analysis of the three local authorities staff involved in the project (small towns) specific self-evaluation questionnaires were submitted to the technical staff and the administrative employees, while to the Majors and other policy makers, qualitative interviews were collected. Having as background the national planning and objectives in this field (national roadmap), the direct screening served to define targeted learning pathways to improve the professional skills and competences in designing, planning and managing the MEEP of small Municipalities.

On that basis, the project has developed guidelines that allow these realities to adopt their plans in the short term, without draining human resources from their structure. The guidelines describe also the steps that Municipalities must follow to join the Covenant of Mayors and the benefits and responsibilities arising from this: primarily, the drafting of the SEAP (Sustainable Energy Action Plan).

The following sections summarize the different steps suggested by the guidelines for the preparation of a MEEP; the guidelines are available for download on the project website [19].

\subsection{Normative References}

The preparation of a MEEP requires a deep knowledge of the general body of laws applicable to the issues under consideration, with a special focus on local laws and regulations. For this purpose, a database of normative references, divided into four groups, was realized within the project:

- International Normative References: at the international level, normative references are connected both to the energy and the environmental sector, and several conferences on climate have led to agreements and commitments of the participating countries to implement less impacting energy policies

- European Normative References: following the conference on the climate, the European Union has adopted a number of directives to reduce energy consumption and to promote the development of renewable sources

- Italian Normative References: the most important Italian rules in the field of energy and environment are reported

- Regional Normative References: the rules and actions implemented by the Umbria Region are reported

The database is published on the website of the project [19], and it was continuously updated during the project.

\subsection{State of the Territory}

The territorial energy planning requires an accurate and deep knowledge of the analyzed reality; it is therefore necessary to initially characterize the territory from a geological point of view, moving then to the assessment of climatological and environmental conditions and, finally, retrieving the demographics and socio-economic data. The collection of all these data in a single document results useful to have a complete and quick view of the territory addressed by the MEEP, and to develop the energy and environmental policies of the territory with an increased awareness.

This phase could be problematic because of the difficulties in finding the above mentioned data. For this reason, the Guidelines identify the sources to be consulted, such as the Italian Institute of Statistics (ISTAT) for demographics and economic activities, the maps with geo-referenced information for the ground use made available by the regional atlas, regional environmental protection agencies for environmental data, etc. At present, indications are supplied only for the Italian situation, but the same suggestions can be easily transferred to other EU member states, by identifying the agencies responsible for each data in every Nation. 


\subsection{Energy Balance}

The core of a MEEP is the analytical energy balance of the municipal territory: a detailed examination of the local situation, including an estimation of demand and supply of energy, both from traditional and renewable sources, of all the activities located inside the Municipality.

The energy balance sheet reports:

- A summary of the all the energy consumed in the territory (energy demand), broken down by sector (agriculture, industry and commerce, tertiary, residential and transport), energy sources and end-use

- The identification of all the energy resources available in the territory and the appraisal of the local energy production (energy supply), with a focus on Renewable Energy Sources (RES)

The energy balance should refer to a predetermined time interval, which usually coincides with the calendar year. The preparation of a MEEP requires the energy balances of at least five years prior to the plan drafting, in order to be able to analyze the trends of supply and demand of energy.

In order to prepare an energy balance that is as detailed as possible, data of consumption and production of energy must be collected from various sources; this is an operation that might be very complex and time-consuming, and not always possible in a direct way. The Guidelines report several suggestions to make this operation easier, indicating the main references from which the data sets can be retrieved and describing in detail the procedures to follow to obtain them. Tables 3 and 4 provide a summary of the required data and sources to consult to estimate, respectively, the supply and demand of energy. As already mentioned for the territorial data, the present suggestions are valid for the Italian situation.

Table 3. Summary of data and sources to assess the energy demand.

\begin{tabular}{|c|c|c|}
\hline Data & Territorial Basis & Main Sources \\
\hline Electrical power consumption and utilities & Municipal & ENEL Distribuzione SpA \\
\hline Natural Gas: consumption and utilities & Municipal & Enel Rete Gas-Italian group F2i Reti \\
\hline $\begin{array}{ll}\text { Petroleum products: consumption } \\
\text { - } & \text { Petrol } \\
\text { - } & \text { Diesel fuel } \\
\text { - } & \text { Agricultural diesel } \\
\text { - } & \text { Heating oil } \\
\text { - } & \text { Fuel oil } \\
\text { - } & \text { LPG for automotive } \\
\text { - } & \text { LPG for heating }\end{array}$ & Provincial & Ministry of Economic Development \\
\hline Solid fuel: consumption & $\begin{array}{l}\text { Provincial } \\
\text { Regional } \\
\text { Regional } \\
\text { Regional }\end{array}$ & $\begin{array}{l}\text { Ministry of Economic Development } \\
\text { ENEA (Italian National Agency for } \\
\text { New Technologies, Energy and } \\
\text { Sustainable Economic Development) } \\
\text { ISTAT (Italian Institute of Statistics) } \\
\text { ISPRA (Institute for Environmental } \\
\text { Protection and Research) }\end{array}$ \\
\hline Number of vehicles & Provincial/Municipal & ACI (Italian Automobile Club) \\
\hline $\begin{array}{l}\text { Population, economic and industrial } \\
\text { activities }\end{array}$ & Provincial/Municipal & ISTAT, Italian Revenue Agency \\
\hline Number of mopeds & National & $\begin{array}{l}\text { ANCMA (Italian Association of Cycles } \\
\text { and Motorcycles) }\end{array}$ \\
\hline
\end{tabular}


Table 4. Summary of data and sources to assess the energy supply.

\begin{tabular}{ccc}
\hline Data & Territorial Basis & Source \\
\hline Photovoltaic & Municipal & GSE (Italian Managing Authority of Energy Services) \\
Solar thermal & Municipal & Municipality \\
Hydroelectric & Municipal & Plant Manager-Private citizen-GSE \\
Wind & Municipal & Plant Manager-Private citizen-GSE \\
Cogeneration & Municipal & Plant Manager-Private citizen-Designer \\
Biomass & Municipal & Plant Manager-Private citizen-GSE \\
Geothermal & Municipal & Plant Manager-Private citizen-Designer \\
Wood/pellet boilers/stoves & Regional/Provincial & Estimate from ISTAT, ENEA, ISPRA \\
\hline
\end{tabular}

\subsection{Estimate of Direct Greenhouse Gases Emissions}

The method used in the MuSAE project for the evaluation of greenhouse gases emissions in the atmosphere involves the use of the emission factors defined by IPCC (Intergovernmental Panel on Climate Change), in the document "Guidelines for National Greenhouse Gas Inventories" [26]. These factors allow to estimate emissions in terms of tonnes of equivalent $\mathrm{CO}_{2}$ (a parameter that summarizes the contribution to global warming from all greenhouse gases) from energy consumption expressed in tonnes of oil equivalent (toe). Advanced procedures exist to support municipal politics in contrasting GHG emissions; for instance, the method already applied in the Municipality of Spoleto (Umbria Region, Italy) could be successfully implemented in the partner Municipalities in order to evaluate the trend of emissions after the MEEPs adoption [27].

\subsection{Definition of Future Energy Scenarios and Proposals for Action}

Different methods can be used to predict the energy consumption of a Municipality in the short and medium term (5-10 years after the adoption of the MEEP), from known data expressed in toe, elaborated by means of the energy balance. In Italy, the most widely used method is the one provided by ENEA [28], together with the methodology based on linear regression. Within the MuSAE project, a slightly different methodology was applied: analyzing the data in the long term (15 years) of the Municipality of Perugia, it was decided for the other involved Municipalities to scale the slope of the line that approximates future consumption trends, making a proportion with the number of inhabitants (Figure 3).

This methodology can be applied for:

- Small- and medium-sized Municipalities located near to those involved in the project, which decide to adopt a MEEP

- Territories with characteristics similar to the case presented by the MuSAE project, where a Municipality that has already adopted an energy plan and owns the energy balance for a significant number of years, transfers its know-how to close small and medium Municipalities. This procedure is one of the examples where the experience of the most skilled Municipality (Perugia) results useful for the smaller ones: without the long-term data obtained from Perugia, the estimation of future energy consumption of the other Municipalities would have been founded on a limited number of years, so lacking of robustness and reliability

After defining the future energy scenarios, the preparatory actions (that ensure a Council the ability to take decisions on actions to be implemented and on measures to be realized) consist of the estimation of the potential that these resources offer in the territory analyzed, and then in the evaluation of the technical and economic feasibility of the interventions. 


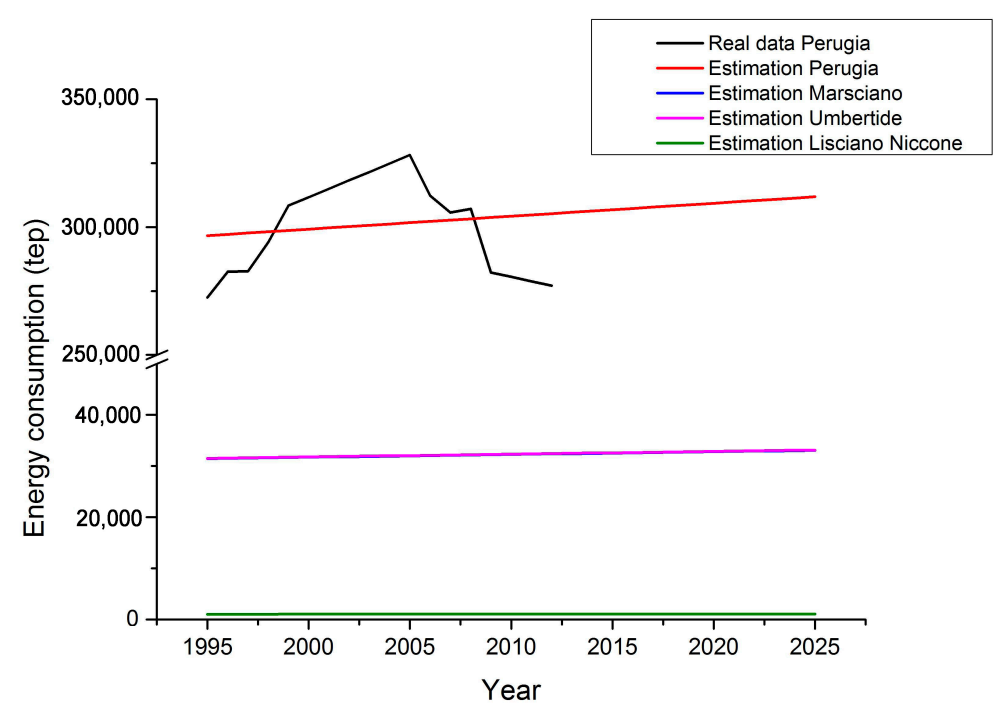

Figure 3. Estimation of future energy consumptions of Marsciano, Umbertide and Lisciano Niccone derived from real data from Perugia.

To this end, the Guidelines suggest some methods for estimating the effectiveness of possible interventions; the results of the first analysis could then be used for defining the most promising strategic sectors, to be studied more in-depth. Afterwards, the interventions are selected and a priority ranking is defined; the priority criteria are based on the achievable effects (for example in terms of reduced fuel consumption and/or emissions), on the economic and technical feasibility, on the presence or absence of regulatory obstacles, on the potential impacts on employment and on any other issues of interest for the Municipality.

Finally, after the assessment of the energy balance, of the emissions, of the trend scenario established in the planning phase and after the definition of the actions that can be profitably implemented in the area, the Municipality administration holds all the tools needed to proceed to the design of interventions. The design stage should be performed through a participatory process with the citizens, which allows the development of a shared and common strategy between the administration and the population.

\section{The Pilot Projects Implemented within the Project}

Each Municipality partner of MuSAE, considering the results of the MEEP and the opinions of the citizens collected during the public meetings, has developed a pilot project in order to disseminate best practices on environmental sustainability and the use of renewable sources. A brief description of each project is reported below; further information can be found on the project website.

\subsection{Municipalities of Perugia and Lisciano Niccone}

Initially, on the basis of the meetings with the population, the orientation of the Municipality of Perugia was to construct a photovoltaic system with a storage. Unfortunately, the Italian legislation regulating the installation of storage systems and their grid connection was not issued until the beginning of 2015, so, this project was discarded.

Thus, the pilot project of the Municipality of Perugia was focused on the use of ICT for the management and monitoring of the electric devices and special systems, by means of the design and installation of an advanced remote control system, applied to a school building (Figure 4), property of the Municipality itself. The building had already been subjected to significant interventions for the building envelope thermal insulation improvement (opaque and transparent surfaces, roof) and for the installation of renewable energy sources (photovoltaic coupled with a heat pump), since the 
improvement of energy efficiency in the building sector is one of the most effective measure to save energy and reduce GHG emissions [29-31]. Within the project, the building was also equipped with a LED lighting system and a remote monitoring of various systems, such as photovoltaic power generation, control of global energy consumption, access control and intrusion detection, video surveillance, possibility of detachment from remote electrical loads connected to a bus line. The application of home automation systems to a public building complex was selected in order to obtain a more effective management; for instance, allowing the system managers to switch off appliances left unintentionally switched on, and, together with the use of efficient lighting system, to reduce substantially the electrical energy consumptions of the building [32].

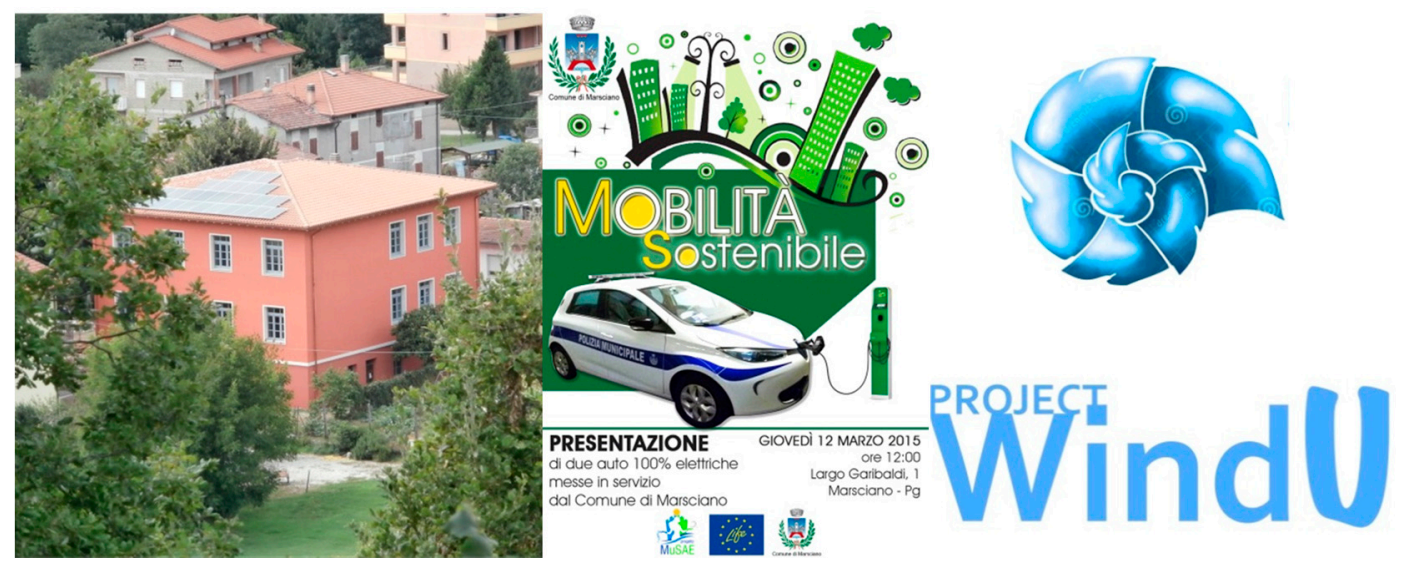

Figure 4. Starting from left to right: school building of the Perugia pilot project; flier for the inauguration of the electric cars in Marsciano; and logo of the WindU project in Umbertide.

The data of the production and consumption of electricity are displayed on an information panel installed inside the school. The data are also published and accessible to the public for institutional reasons and to promote the concept of "know, control, save".

The Municipality of Lisciano Niccone, in the footsteps of what was implemented by the Municipality of Perugia, also selected the realization of a system of remote monitoring and management of facilities, dedicated to a school building.

\subsection{Municipality of Marsciano}

The MEEP of Marsciano has evidenced that the transport sector is of high importance in terms of energy, environmental and livability of the city. The first stage of this project consisted of the installation of two electric vehicle charging stations by ENEL S.p.A., for both public and private use, at no cost to the town. This operation was followed by the purchase of two electric cars (Figure 4) and the scrapping at the same time of two old municipally-owned cars, which not only provides significant environmental benefits but also allows savings in operating costs of approximately $€ 6000$ per year. It should be noted, however, that the project's main value is more demonstrative than economic, since the purchase of these two 100\% electric cars can make all citizens aware of the current potential of electric transportation in terms of the reducing of noxious emissions, greenhouse gases and noise pollution.

\subsection{Municipality of Umbertide}

The participatory forums held by the Municipality of Umbertide brought to light the townspeople's priority interest in wind energy. This influenced the decision to install at the Mola Casanova renewable energy demonstration center-which already hosts a hydroelectric plant and a geothermal resource-a small demonstration wind farm, whose function is to make known and 
demonstrate to the public (especially to young students) this renewable energy resource, scarcely used within the Municipality. The project was called WindU, from wind + U(mbertide) (Figure 4) was developed by the Municipality with the participation of professionals and companies of the territory, beyond being opened to suggestions and proposals from the citizens. During the development of the final project, it was seen that the implementation of wind power, together with solar photovoltaic energy, is a significant "plus" in terms of productivity and innovation, and therefore it was decided to integrate the wind turbine envisaged in the preliminary stage with a series of photovoltaic panels installed alongside it. The project, therefore, provides for the installation of a $1 \mathrm{~kW}$ wind turbine and four $250 \mathrm{~W}$ photovoltaic solar panels, for a total of $2 \mathrm{~kW}$ of maximum capacity. The energy produced will be stored in four 200 Ah batteries. This energy will be used to charge the electric bikes at the Mola Casanova center.

\section{Information and Dissemination Actions}

Discussion with local communities and dissemination of methodologies and results were key actions of MuSAE; these activities were aimed at increasing the awareness of citizens about energy and environmental issues and at involving all stakeholders (administrators, engineers, entrepreneurs, academics), primarily in the definition of the energy and environmental planning included in the MEEP.

As a consequence, the energy-environment planning process in the four partner Municipalities has been accompanied and stimulated by structured participatory actions with the townspeople and stakeholders throughout the entire duration of the project.

The Participatory Forums have allowed the sharing of objectives and the MuSAE results.

Forums were organized similarly in all locations, although with different audiences on the different occasions. The Forum meetings were publicized and invitations were sent to key stakeholders, along with the Forum program. The agendas always provided for an initial brief presentation on the state of the art of the MuSAE project, on the feedback from previous meetings and on the results expected and achieved by project actions. Afterwards, a study session was proposed, often consisting of smaller groups of 5-8 persons, or with full attendance (chosen according to the number of participants) in order to reach shared evaluations, through an "evaluative query" supported by grids and matrices created ad hoc (e.g., Strengths, Weaknesses, Opportunities and Threats (SWOT) matrices, targeted questionnaires). The feedback from the study groups, or the discussions generated by the plenary debates, provided useful information to the Municipalities involved regarding the priorities of the townspeople in relation to the issues of energy planning and management. The Forum reports are available on the project website.

Eight seminars were organized by the Region of Umbria in October and November 2014 in six Umbrian Municipalities not participating to the project, but interested on its implementation. These seminars, which were held for both municipal authorities and technicians, had the aim of disseminating the contents of the MEEPSs, demonstrating how they could represent the support tool for the energy strategies of each Municipality. The seminars constituted also an opportunity to compare the different municipal situations and to increase the technical know-how.

Finally, two final events were organized, one at the local level in Perugia and one at the European level in Brussels (Figure 5).

The final National Conference was held on 17 April 2015. The event was focused on the importance of transferring energy planning knowledge and experience with the aim of helping the Municipalities of Umbria in drafting MEEPs. The conference was an opportunity to discuss and compare national energy strategies, reviving the current interest in the topic. Conference attendants included the technicians of local authorities, as well as many professionals in the energy sector. 


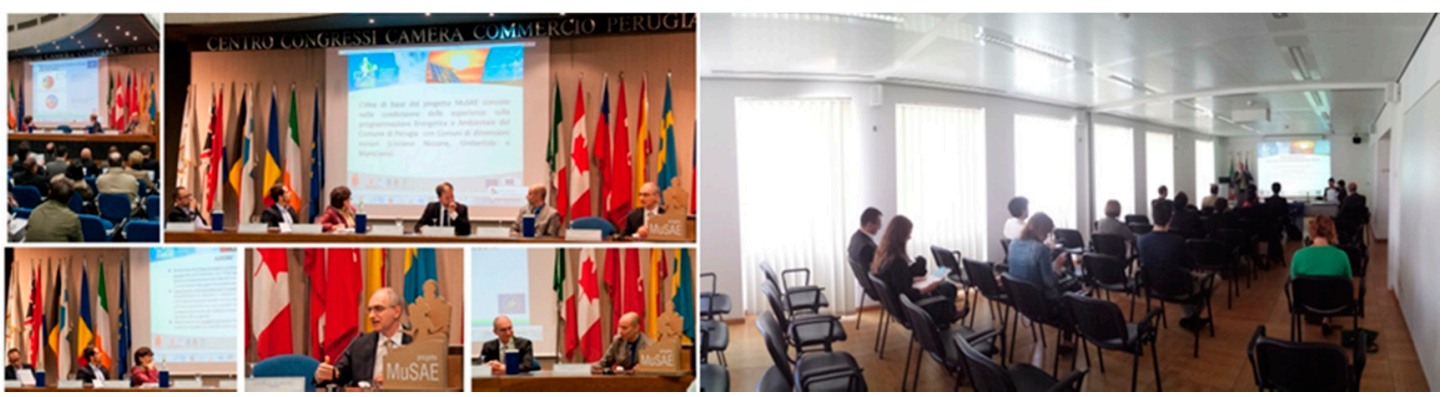

Figure 5. Pictures of the Italian (left) and European (right) Final Conferences.

The International Conference, named "Public Authorities and Citizens for Europe's 2020 Objectives-Life Projects Experiences", was a side event in the framework of the 2015 European Sustainable Energy week. The event, involving three other projects related to similar topics, namely Perht [33], EcoLife [34] and RecOil [35], was aimed at showing the results of the projects and facilitating national and international networking, involving both local governments that implement energy strategies and citizens as active agents in the application of good practices.

\section{Conclusions}

The MuSAE project represented a crucial opportunity to raise awareness of the medium-small administrations towards energy planning, a result confirmed by the interest in the population that responded significantly to participatory forums and meetings organized throughout the duration of the project.

The issues developed by the MuSAE project, and in particular the attention given to Municipal Energy and Environmental Plans, provided support to the energy planning activities that the Umbria Region is required to implement. The MuSAE project experience has shown the need for all local actors to become involved to achieve the common objective of increasing energy efficiency and reducing greenhouse gases emissions, proving that the essential regional energy planning must be combined with local energy planning.

The feedback received from this experience has taken shape in the identification of a specific measure in the 2014-2020 Regional Energy and Environmental Strategy (REES). The REES is the Umbria Region new planning tool which sets the goal of achieving by 2020 a ratio of $15.2 \%$ between the energy produced from renewable energy sources and the gross final consumption of energy, a percentage higher than the target of $13.7 \%$, established by the EU with the burden sharing. The strategy identifies four different types of regional measures, describing them in relation to the four main macro-areas (domestic/residential, industrial and services, agriculture and transport), and indicating the actions to carry on. More specifically, among the measures aimed at improving Governance, the following action is proposed: "Drafting of plans and programs for analysis of emissions in the major sectors, of the overall energy consumption, and of public utilities consumptions, identifying possible measures for increasing energy efficiency". This measure intends to support the implementation of energy efficiency measures, intelligent energy management and the use of renewable energy through the drafting of Energy and Environmental Plans in the Municipalities of Umbria. The long-term benefits will consist of a higher environmental awareness and culture among the people and those working in the field, the energy info desks, the possible future investments derived from the MuSAE project experience, in order to contribute significantly to reach and go beyond the targets set by the strategy "Europe 20/20/20".

Acknowledgments: Project MuSAE ("Municipalities Subsidiarity for Actions on Energy" (code LIFE11 ENV/IT/000016)) was funded by the European Union Life+ 2011 Programme.

Author Contributions: All the authors contributed equally to this work. 
Conflicts of Interest: The authors declare no conflict of interest.

\section{References}

1. Mirakyan, A.; de Guio, R. Integrated energy planning in cities and territories: A review of methods and tools. Renew. Sustain. Energy Rev. 2013, 22, 289-297. [CrossRef]

2. Sperling, K.; Hvelplund, F.; Mathiesen, B.V. Centralisation and decentralisation in strategic municipal energy planning in Denmark. Energy Policy 2011, 39, 1338-1351. [CrossRef]

3. Brugmann, J. Planning for sustainability at the local government level. Environ. Impact. Assess. Rev. 1996, 16, 363-379. [CrossRef]

4. Collier, U. Local authorities and climate protection in the European union: Putting subsidiarity into practice? Local Environ. 1997, 2, 38-57. [CrossRef]

5. Argyriou, I.; Fleming, P.; Wright, A. Local climate policy: Lessons from a case study of transfer of expertise between UK local authorities. Sustain. Cities Soc. 2012, 5, 87-95. [CrossRef]

6. Energy Cities Homepage. Available online: http://www.energy-cities.eu/ (accessed on 24 November 2015).

7. Climate Alliance Homepage. Available online: http://www.climatealliance.org/ (accessed on 24 November 2015).

8. ICLEI-Local Governments for Sustainability Homepage. Available online: http://www.iclei.org/ (accessed on 24 November 2015).

9. Covenants of Mayors Homepage. Available online: http://www.covenantofmayors.eu/ (accessed on 24 November 2015).

10. Brandoni, C.; Polonara, F. The role of municipal energy planning in the regional energy-planning process. Energy 2012, 48, 323-338. [CrossRef]

11. Hiremath, R.B.; Shika, S.; Ravindranath, N.H. Decentralized energy planning; modelling and application-a review. Renew. Sustain. Energy Rev. 2007, 11, 729-752. [CrossRef]

12. Klevas, V.; Antinucci, M. Integration of national and regional energy development programs in Baltic States. Energy Policy 2004, 32, 345-355. [CrossRef]

13. Nilsson, J.S.; Martensson, A. Municipal energy-planning and development of local energy-system. Appl. Energy 2003, 76, 179-187. [CrossRef]

14. Local Government Association (LGA). A Climate of Change: Final Report of the LGA Climate Change Commission. Available online: http://www.local.gov.uk/publications/-/journal_content/56/ 10180/3367105/PUBLICATION (accessed on 24 November 2015).

15. Comodi, G.; Cioccolanti, L.; Polonara, F.; Brandoni, C. Local authorities in the context of energy and climate policy. Energy Policy 2012, 51, 737-748. [CrossRef]

16. Feng, Y.P.; Wu, Y.P.; Liu, Y. Energy-efficiency supervision systems for energy management in large public buildings: Necessary choice for China. Energy Policy 2009, 37, 2060-2065.

17. West, J.; Bailey, I.; Winter, M. Renewable energy policy and public perceptions of renewable energy: A cultural theory approach. Energy Policy 2010, 38, 5739-5748. [CrossRef]

18. Brandoni, C.; Polonara, F. Technical and economic aspects of municipal energy planning. Int. J. Sustain. Dev. Plan. 2012, 7, 221-236. [CrossRef]

19. Project MuSAE Homepage. Available online: http://www.life-musae.it (accessed on 12 August 2015).

20. Asdrubali, F.; Baldinelli, G.; D'Alessandro, F.; Scrucca, F. Life cycle assessment of electricity production from renewable energies: Review and results harmonization. Renew. Sustain. Energ. Rev. 2015, 42, 1113-1122. [CrossRef]

21. Moncada, L.G.G.; Asdrubali, F.; Rotili, A. Influence of new factors on global energy prospects in the medium term: Comparison among the 2010, 2011 and 2012 editions of the IEA's World Energy Outlook reports. Econ. Policy Energy Environ. 2013, 3, 67-89.

22. The European Parliament and the Council of the European Union. Directive 2009/28/EC of the European Parliament and of the Council of 23 April 2009. On the promotion of the use of energy from renewable sources and amending and subsequently repealing Directives 2001/77/EC and 2003/30/EC (Text with EEA relevance). Off. J. Eur. Union 2009, 140, 47. 
23. Ministero dello Sviluppo Economico. Definizione e Qualificazione Degli Obiettivi Regionali in Materia di Fonti Rinnovabili e Definizione della Modalità di Gestione dei casi di Mancato Raggiungimento Degli Obiettivi da Parte Delle Regioni e Delle Provincie Autonome; Ministero dello Sviluppo Economico: Roma, Italy, 2012. (In Italian)

24. Italian Government. Legge 9 Gennaio 1991 n.10 - Norme per L'attuazione del Piano Energetico Nazionale in Materia di uso Nazionale Del'energia, di Risparmio Energetico e di Sviluppo Delle Fonti RInnovabili di Energia; Official Gazette of the Italian Republic: Roma, Italy, 1991. (In Italian)

25. The Municipality of Perugia. Municipal Energy and Environmental Plan of the Municipality of Perugia. Available online: http://www.comune.perugia.it/pagine/piano-energetico-ambientale (accessed on 12 August 2015).

26. Intergovernmental Panel on Climate Change (IPCC). 2006 IPCC Guidelines for National Greenhouse Gas Inventories. Available online: http:/ / www.ipcc-nggip.iges.or.jp/public/2006gl/ (accessed on 12 August 2015).

27. Asdrubali, F.; Presciutti, A.; Scrucca, F. Development of a greenhouse gas accounting GIS-based tool to support local policy making-Application to an Italian municipality. Energy Policy 2013, 61, 587-594. [CrossRef]

28. Agenzia Nazionale per le Nuove Tecnologie, L'energia e lo Sviluppo Economico Sostenibile (ENEA). Guida per la Pianificazione Energetica Comunale; ENEA: Roma, Italy, 1997. (In Italian)

29. Asdrubali, F.; Baldinelli, G.; Bianchi, F.; Sambuco, S. A comparison between environmental sustainability rating systems LEED and ITACA for residential buildings. Build. Environ. 2015, 86, 98-108. [CrossRef]

30. Asdrubali, F.; D'Alessandro, F.; Schiavoni, S. A review of unconventional sustainable building insulation materials. Sustain. Mater. Technol. 2015. [CrossRef]

31. Battista, G.; Evangelisti, L.; Guattari, C.; Basilicata, C.; de Lieto Vollaro, R. Buildings energy efficiency: Interventions analysis under a smart cities approach. Sustainbility 2014, 6, 4694-4705. [CrossRef]

32. Salata, F.; de Lieto Vollaro, A.; Ferraro, A. An economic perspective on the reliability of lighting systems in building with highly efficient energy: A case study. Energy Convers. Manag. 2014, 84, 623-632. [CrossRef]

33. Project Perht Homepage. Available online: http://www.perht-lifeplus.org (accessed on 12 August 2015).

34. Project Ecolife Homepage. Available online: http:/ / www.ecolifestyles.eu (accessed on 12 August 2015).

35. Project RecOil Homepage. Available online: http://www.recoilproject.eu/ (accessed on 12 August 2015).

(C) 2015 by the authors; licensee MDPI, Basel, Switzerland. This article is an open access article distributed under the terms and conditions of the Creative Commons by Attribution (CC-BY) license (http://creativecommons.org/licenses/by/4.0/). 